Journal of Organometallic Chemistry, 241 (1983) 301-312

Elsevier Sequoia S.A., Lausanne - Printed in The Netherlands

\title{
SYNTHESIS OF CYCLIC AND POLYMERIC DERIVATIVES OF 1,2-DITHIOL-o-CARBORANE
}

\author{
FRANCESC TEIXIDOR * and RALPH W. RUDOLPH ** \\ Department of Chemistry, The University of Michigan, Ann Arbor, Michigan 48109 (U.S.A.) \\ (Received July 25th, 1982)
}

\section{Summary}

Cyclic compounds containing two symmetrically placed 1,2-dicarbaclosododecaboranyl or two 7,8-dicarbaundecaborate(10) moieties have been synthesized. The bridges between the carborane cages are $\mathrm{S}-\mathrm{S}$ or $\mathrm{S}-\mathrm{CH}_{2}-\mathrm{CH}_{2}-\mathrm{S}$ for the undegraded species, and $\mathrm{S}-\mathrm{CH}_{2}-\mathrm{S}$ or $\mathrm{S}-\mathrm{CH}_{2} \mathrm{CH}_{2}-\mathrm{S}$ for the degraded ones. The sulfur atoms in all cases are bonded to the carborane carbons. Unlike preparations previously reported in the literature, degradation to the partially degraded $o$-carborane cages proceeds without requiring treatment by a conventional base. Ring closure and the presence of sulfur atoms linked to the o-carborane carbons are believed to be necessary in order for the degradation to occur. When the number of bonds involved in the bridge between the two cages was seven, no cyclization occurred despite the presence of a square planar nickel template, the reaction instead producing a polymeric material.

\section{Introduction}

Searches for new and more efficient methods of obtaining industrially important starting materials has led in recent years to a considerable increase in the numbers of papers on catalysis [1]. In a recent review, Muetterties [2] has pointed out that there are some catalytic reactions (for example, hydrogenation of $\mathrm{N}_{2}$ to yield ammonia) that occur with catalysts in the solid state but that do not occur with homogeneous catalysts, the conclusion being that for the reaction to occur, more than one catalytic metallic center must be in close proximity. As a consequence of this argument, it would appear that a homogeneous catalyst with two or more catalytic centers held in a fixed spatial arrangement might show increased selectivity compared to heteroge-

\footnotetext{
* Pcrmancnt address: Departament de Quimica Inorganica, Universitat Autonoma de Barcelona, Cerdanyola, Barcelona (Spain).

** Deceased, 11 May 1981.
} 


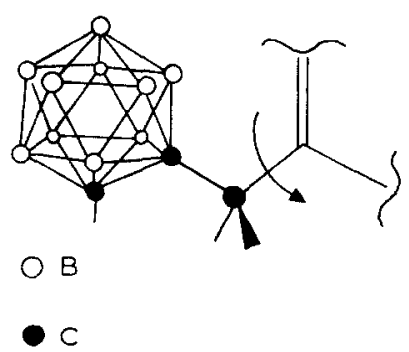

Fig. 1. An o-carboranyl moiety linked to a porphyrin ring through a $\mathrm{CH}_{2}$ bridge showing the possibility of rotation of the cage.

neous catalysts and expand the area of usefulness of this type of catalyst. An obvious class of compounds to investigate are metal clusters: they are soluble, they have metal atoms in close proximity and they have delocalized electron systems similar to metals. However, not only metal clusters exhibit the preceding characteristics: boron hydrides as well have a delocalized system of electrons and derivatives of these compounds incorporating appropriate metals have been shown to have catalytic activity, e.g., 3,3-( $\left.\mathrm{PPh}_{3}\right)_{2}-3-\mathrm{H}-3,1,2-\mathrm{RhC}_{2} \mathrm{~B}_{9} \mathrm{H}_{11}$ [3]. Although this molecule has only one metal atom per molecule, comparable catalytic activity has been observed in $\left[\left(\mathrm{PPh}_{3}\right) \mathrm{RhC}_{2} \mathrm{~B}_{9} \mathrm{H}_{11}\right]_{2}[4]$.

The properties of metallocarboranes containing more than one metal atom per molecule have been reviewed by Dunks and Hawthorne [5]. One characteristic of all of the metallocarboranes surveyed is that the metal atom plays an important role in holding the molecule together, and therefore processes characteristic of catalysts, such as addition of the substrate, either split the molecule or do not occur because the metal is coordinatively saturated. In this laboratory, we are approaching the problem by seeking compounds in which the metal atoms can be kept sufficiently close together for the catalytic center to have the necessary catalytic activity but for which the catalyzed reaction does not endanger the existence of the catalyst molecule. Progress towards this objective has been made with the synthesis of ligands such as $\mathrm{H}_{2}\left(\mathrm{CH}_{2}-\mathrm{C}_{2} \mathrm{~B}_{10} \mathrm{H}_{11}\right)_{4}$ [6] which can be incorporated into a metal complex after partial degradation of the carborane cage [7]. However, since the metallo-carborane moiety in the compound reported was linked to a porphyrin ring by only one bond (Fig. 1), the relative distance of the metal atoms could not remain fixed.

In this paper we present the synthesis of ligands that can coordinate to two metal atoms in such a way that their spatial arrangement is fixed, allowing the two metals to be separated by a short distance while retaining their association with a delocalized system of electrons.

\section{Experimental}

\section{General}

Elemental analyses were performed by Galbraith Laboratories, Inc., Knoxville, Tennessee. Melting points were done in sealed tubes and are uncorrected. Infrared spectra were obtained using a Perkin-Elmer Model 457. The ' $\mathrm{H}$ and "B NMR spectra were obtained using either a JEOL FX-90Q, or a Bruker WM-360. Mass 
spectra were recorded with a Finnigan 4023 GC/MS.

$o$-Carborane (Dexil Chemical Corporation) was sublimed before use; 1,2-dithiol$o$-carborane (I) was prepared from $o$-carborane according to the literature [8]. The n-butyllithium 1.6 M solution in hexane (Aldrich) was used as received. Absolute ethyl ether (Mallinckrodt) and benzene was stored on a vacuum line with $\mathrm{Na}$ /benzophenone and distilled in vacuo prior to use. All other reagents and solvents were reagent grade and used as received. Reactions were conducted under a $\mathrm{N}_{2}$ atmosphere.

\section{$1,1^{\prime}, 2,2^{\prime}$-tetrathio-bis-o-carborane (II)}

To a nitrogen-blanketed solution containing $0.20 \mathrm{~g}(0.96 \mathrm{mmol})$ of 1,2 -dithiol-ocarborane (I), in $40 \mathrm{ml}$ of dry benzene, were added all at once $0.27 \mathrm{~g}$ (1 mmol) of $\mathrm{I}_{2}$ followed immediately by $0.5 \mathrm{~g}$ of sodium bicarbonate. The reaction vessel was a 3-necked flask fitted with reflux condenser and filled with glass beads. Nitrogen was allowed to bubble through the solution by means of an inlet inserted through one neck. The $\mathrm{N}_{2}$ flow was regulated to agitate the solution but without forming a liquid obstruction in the lower part of the cooling system. The solution was heated under reflux for $24 \mathrm{~h}$ after which it was still iodine colored. At that point, a drying tube was connected to the third neck of the flask and the $\mathrm{N}_{2}$ rate was increased sufficiently to evaporate most of the benzene. Before attaining dryness the apparatus was dismantled (under $\mathrm{N}_{2}$ ) and the residual benzene was pumped off. The solid was collected in a glove bag and then sublimed at $90^{\circ} \mathrm{C}(0.01$ Torr) until the residue lost most of the brownish color. The residue was then collected, put in a Soxhlet thimble and extracted with dry benzene overnight. Evaporation and drying in vacuo gave $110 \mathrm{mg}$ (55\% yield) of a pale tan solid. (The color was probably due to a small residual $\mathrm{I}_{2}$ impurity.) The product sublimed at $180^{\circ} \mathrm{C}(0.01$ Torr) very slowly; m.p. $235^{\circ} \mathrm{C}$ with decomposition. It reacted with moisture and had to be stored under vacuum or very dry $\mathrm{N}_{2}$.

Analysis: Found B, 52.0; S, 30.8. $\mathrm{C}_{4} \mathrm{H}_{20} \mathrm{~B}_{20} \mathrm{~S}_{4}$ calcd: $\mathrm{B}, 52.4, \mathrm{~S}, 31.0 \%$. Mass spectrum, basc peak envelope centered at 206.1 (100\%), molecular peak cnvelope centered at $412.3(50 \%)$, cut off peak at 418 . Intensity ratio of $412 / 418=66$.

\section{Reaction of 1,2-dithiol-o-carborane with liquid ammonia.}

Ammonium 1,2-dithiolate-o-carborane (III). In a $50 \mathrm{ml}$ three-necked flask with the middle neck connected to a dry ice cold-finger condenser, $0.2 \mathrm{~g}(0.96 \mathrm{mmol})$ of 1,2-dithiol-o-carborane (I) were placed under $\mathrm{N}_{2}$. The flask was flushed with $\mathrm{N}_{2}$ for 15 min before $\mathrm{NH}_{3}(\mathrm{~g})$ was introduced via the one neck and $\mathrm{NH}_{3}(1)$ allowed to condense on the cold finger. About $15 \mathrm{ml}$ of liquid ammonia were condensed $\left(-77^{\circ} \mathrm{C}\right)$. The solution was stirred for $30 \mathrm{~min}$ with a magnetic stirrer and the $\mathrm{NH}_{3}$ then allowed to evaporate (about $1 \mathrm{~h}$ ) by removing the dry ice from the condenser. Last traces of $\mathrm{NH}_{3}$ were swept out using a $\mathrm{N}_{2}$ stream to give a product ranging in color from light yellow to white.

Analysis: Found: $\mathrm{B}, 44.37 ; \mathrm{N}, 11.15 ; \mathrm{S}, 26.42 . \mathrm{C}_{2} \mathrm{H}_{18} \mathrm{~B}_{10} \mathrm{~N}_{2} \mathrm{~S}_{2}$ calcd.: $\mathrm{B}, 44.63 ; \mathrm{N}$, $11.57 ; \mathrm{S}, 26.44 \%$.

Tetramethylammonium 7,7'; 8,8'-di-(1,2-dithioethane)-bis(7,8-dicarbaundecaborate(10)) (IV). The total amount of III obtained from $0.2 \mathrm{~g} \mathrm{I}(0.96 \mathrm{mmol})$ was dissolved in $40 \mathrm{ml}$ of absolute ethanol in a $100 \mathrm{ml}$ 3-neck flask equipped with a condenser, and $0.1 \mathrm{ml}(1.16 \mathrm{mmol})$ of 1,2-dibromoethane were added. The solution was stirred 
overnight, during which time the yellowish color of the solution was observed to fade substantially. (In some runs a small amount of solid is obtained.) The solution then was transferted to a beaker and $150 \mathrm{ml}$ of distilled water added. (If a turbidity appeared the solution was filtered.) [9] While $\mathrm{N}_{2}$ was bubbled through the solution an excess of $\mathrm{Me}_{4} \mathrm{NCl}$ in $20 \mathrm{ml}$ of water was added and a solid precipitated. After the solution stood for 15 min the solid was collected by filtration and dried in vacuum $\left(100^{\circ} \mathrm{C}, 0.01\right.$ Torr for $\left.5 \mathrm{~h}\right)$. The solid was recrystallized from acetic acid affording 94 mg (44\% yield). M.p.(dec) $255^{\circ} \mathrm{C}$. Analysis: Found: C, 28.18: H, 7.88; B. 28.87; N, 4.02: S, 19.20. $\mathrm{C}_{16} \mathrm{H}_{52} \mathrm{~B}_{18} \mathrm{~N}_{2} \mathrm{~S}_{4} \cdot 4.5 \mathrm{H}_{2} \mathrm{O}$ calcd.: C, 28.42; H. 9.03: B, 28.78: N, 4.14: S. $18.95 \%$.

Tetramethylammonium $7,7^{\prime} ; 8,8^{\prime}$-di-(dithiomethane)-bis( 7,8 -dicarbaundecaborate(10)) $(\mathrm{V})$. The procedure was similar to that for the preparation of IV. The amount of III obtained from $0.35 \mathrm{~g}$ of I $(1.68 \mathrm{mmol})$ was dissolved in $40 \mathrm{ml}$ of absolute ethanol and $3 \mathrm{ml}$ (46.8 mmol, 28 times excess) of dichloromethane and $1.9 \mathrm{~g}$ of $\mathrm{NaI}$ were added to the stirred solution which was maintained at reflux until the vellow color disappeared $(3.5 \mathrm{~h})$.

The subsequent workup was similar to that of compound IV. The product was recrystallized using methanol/ethanol $2 / 1$ with heating followed by evaporation and cooling (sometimes repeatedly). Heating at $150^{\circ} \mathrm{C}$ for 15 h gave $227 \mathrm{mg}$ ( $49 \%$ yield) of a dry, white solid which melted at $260-261^{\circ} \mathrm{C}$ with decomposition.

Analysis: Found: C, 29.40; H, 8.50; B, 34.56; N, 4.90: S, 22.34. $\mathrm{C}_{14} \mathrm{H}_{48} \mathrm{~B}_{18} \mathrm{~N}_{2} \mathrm{~S}_{4}$ calcd.: C, 29.66: H, 8.47; B. 34.32; N, 4.94; S, 22.60\%.

TABLE 1

MASS SPECTRA VALUES

\begin{tabular}{|c|c|c|c|c|}
\hline Compound ${ }^{\text {a.e }}$ & $\begin{array}{l}\text { EI } \\
m / e\end{array}$ & Assignment ${ }^{R}$ & $\begin{array}{l}\mathrm{Cl} \\
m / e\end{array}$ & Assignment \\
\hline $\mathrm{VI}^{h}$ & $\begin{array}{l}223.1(100 \%) \\
239.1(75 \%) \\
253.2(27 \%) \\
442.3(2 \%)\end{array}$ & $\begin{array}{l}M / 2-1 \\
M / 2+\mathrm{CH}_{2}+1 \\
M / 2+\mathrm{S}-3 \\
M-6\end{array}$ & $\begin{array}{l}223(27.4 \%) \\
239.1(100 \%) \\
252(84 \%) \\
268(5 \%)\end{array}$ & $\begin{array}{l}M / 2-1 \\
M / 2+\mathrm{CH}_{2}-\mathrm{I} \\
M / 2+\mathrm{S}-4 \\
M / 2+\mathrm{CH}_{2} \mathrm{~S}-2\end{array}$ \\
\hline VII ${ }^{c}$ & $\begin{array}{l}206.3(80 \%) \\
224.2(100 \%) \\
252(32 \%) \\
414(7 \%)\end{array}$ & $\begin{array}{l}M / 2-4 \\
M / 2+\mathrm{CH}_{2} \\
M / 2+\mathrm{CH}_{2} \mathrm{~S}-4 \\
M-6\end{array}$ & & \\
\hline $\mathrm{IX}^{d}$ & $\begin{array}{l}234.2(100 \%) \\
467.2(0.3 \%)\end{array}$ & $\begin{array}{l}M / 2 \\
M-1\end{array}$ & $\begin{array}{l}235.2(100 \%) \\
265.2(36.9 \%) \\
280.2(31.6 \%) \\
292.2(22.8 \%)\end{array}$ & $\begin{array}{l}M / 2+1 \\
M / 2+\mathrm{S}-1 \\
M / 2+\mathrm{CH}_{2} \mathrm{~S} \\
M / 2+\mathrm{C}_{2} \mathrm{H}_{4} \mathrm{~S}-2\end{array}$ \\
\hline
\end{tabular}

"The numbers in parentheses represent the intensities referred to the hase peak in the spectrum. ${ }^{b} \mathrm{M}={ }^{12} \mathrm{C}_{8}{ }^{1} \mathrm{H}_{30}{ }^{10} \mathrm{~B}_{4}{ }^{11} \mathrm{~B}_{14}{ }^{32} \mathrm{~S}_{4} \quad \mathrm{M}=448$. ${ }^{c} \mathrm{M}={ }^{12} \mathrm{C}_{6}{ }^{1} \mathrm{H}_{26}{ }^{10} \mathrm{~B}_{4}{ }^{11} \mathrm{~B}_{14}{ }^{32} \mathrm{~S}_{4} \quad \mathrm{M}=420$. " $\mathrm{M}=$ ${ }^{12} \mathrm{C}_{8}{ }^{1} \mathrm{II}_{28}{ }^{10} \mathrm{~B}_{4}{ }^{11} \mathrm{~B}_{16}{ }^{37} \mathrm{~S}_{4} \mathrm{M}=468$. "The atums in the fragntents are considered ${ }^{12} \mathrm{C}$. ${ }^{1} \mathrm{H}$ and ${ }^{22} \mathrm{~S}$. $\mathrm{EI}=$ electron impact; $\mathrm{CI}=$ chemical ionization. ${ }^{8}$ Numbers subtracted represent unit atomic weights (protons) missing. 
Reaction of $7,7^{\prime} ; 8,8^{\prime}$-di- $\mu-(1,2$-dithioethane)-bis-(7,8-dicarbaundecaborate(10)) with hydrochloric acid

A solution of $30 \mathrm{ml}$ of water saturated with $\mathrm{NaCl}$ was added to a suspension of 20 $\mathrm{mg}$ of compound IV in $20 \mathrm{ml}$ of ethyl ether. After stirring for $10 \mathrm{~min}$ a few drops of concentrated $\mathrm{HCl}$ (aq) were added and both layers became clear. The flask was shaken vigorously and then the ethereal layer was separated and dried over anhydrous magnesium sulfate. Filtration and evaporation of the ether solution gave an oil. Toluene was added to the oil and evaporated repeatedly ( 6 times) until a white solid was obtained, (VI), see Table 1 for characterization.

Reaction of $7,7^{\prime} ; 8,8^{\prime}$-di- $\mu-(1,2$-dithiomethane) bis-(7,8-dicarbaundecaborate(10)) with hydrochloric acid

The same procedure as in the previous case was used. The solid obtained was highly hygroscopic, (VII). See Table 1 for characterization.

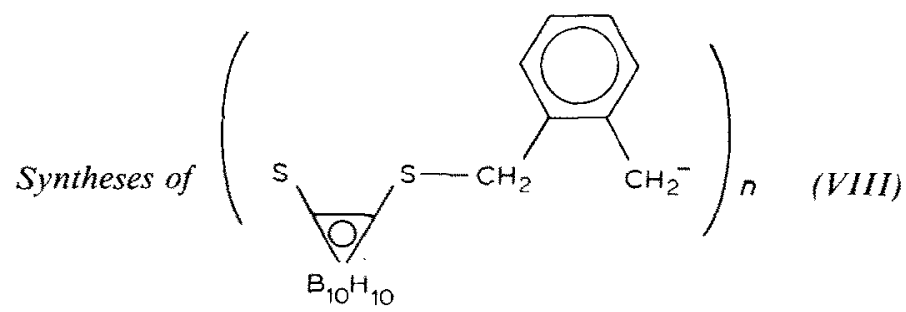

Under $\mathrm{N}_{2}, 0.12 \mathrm{~g}(2.14 \mathrm{mmol})$ of $\mathrm{KOH}$ were added to a solution of $0.15 \mathrm{~g}(0.72$ $\mathrm{mmol}$ ) of 1 in $15 \mathrm{ml}$ of methanol. The solution was stirred for $25 \mathrm{~min}$ and then $\mathrm{CO}_{2}$ was passed through the solution to eliminate excess $\mathrm{KOH}$ after which $0.21 \mathrm{~g}(0.77$ $\mathrm{mmol})$ of $\alpha, \alpha^{\prime}$-dibromo-o-xylene in methanol $(30 \mathrm{ml})$ were added to the solution (total volume of reaction $40-45 \mathrm{ml}$ ). After a few minutes a white precipitate was formed and the stirring was continued for $2 \mathrm{~h}$. The precipitate was collected by filtration and washed three times with $5 \mathrm{ml}$ portions of methanol. Drying at 0.01 Torr yielded $142 \mathrm{mg}$ of a white solid (63\% yield), M.p. $>260^{\circ} \mathrm{C}$. Compound VIII is insoluble in most organic solvents but slightly soluble in THF.

Analysis: Found: C, 38.09; H, 5.85; B, 33.94; S, 19.97. $\mathrm{C}_{10} \mathrm{H}_{18} \mathrm{~B}_{10} \mathrm{~S}_{2}$ calcd.: C, $38.71 ; \mathrm{H}, 5.81 ; \mathrm{B}, 34.83 ; \mathrm{S}, 20.64 \%$.

Upon evaporating the supernatant solution a white solid was obtained. The ${ }^{11} \mathrm{~B}$ NMR and IR of the soluble fraction proved to be a mixture of partially degraded and undegraded species ( $1 / 2$ respectively) [10]. The ${ }^{\prime} H$ NMR also indicated that at least two more species besides unreacted $\alpha, \alpha^{\prime}$-dibromo- $\rho$-xylene were contained.

Syntheses of $1,1^{\prime} ; 2,2^{\prime}$-di- $\mu$-(1,2-dithioethane)-bis-o-carborane (IX)

To a solution of $0.205 \mathrm{~g}(0.986 \mathrm{mmol})$ of 1,2-dithiol-o-carborane in absolute ethanol $(40 \mathrm{ml})$ were added $0.166 \mathrm{~g}(2.9 \mathrm{mmol})$ of $\mathrm{KOH}$. After a few minutes the solution appeared pale yellow; after $30 \mathrm{~min}, \mathrm{CO}_{2}$ was bubbled through the solution to eliminate the excess $\mathrm{KOH}$ by filtration as the carbonate. Ethanol was added to restore the initial volume and also $0.1 \mathrm{ml}(1.16 \mathrm{mmol})$ of 1,2-dibromoethane. The reaction mixture was stirred overnight and the product was recovered by evaporation. By "B NMR the product composition was $42 \%$ IV and $52 \%$ the potassium salt of III [11]. The flask was refilled with absolute ethanol $(40 \mathrm{ml})$ and was heated at 
reflux for $3 \mathrm{~h}$. After cooling, a white solid (soluble in water and giving no precipitate adding $\mathrm{Me}_{4} \mathrm{~N}$ ) was separated by filtration. The ethanolic filtrate was evaporated and dried in vacuum. The ${ }^{11} \mathrm{~B}$ NMR of the product showed it to be composed of IV $(50 \%)$ and IX (50\%). The solid mixture was extracted with benzene to leave IV as a solid which was collected by filtration and a solution which after being evaporated gave IX. See Table 1 for characterization of IX.

\section{Results}

The reaction of 1,2-dithiol-o-carborane (I) with liquid ammonia quantitatively gave ammonium 1,2-dithiolate-o-carborane (III) (eq. 1). Further reaction of III with

$\mathrm{H}_{10} \mathrm{~B}_{10} \mathrm{O}\left(\mathrm{NH}_{3} \underset{\mathrm{SH}}{\mathrm{SH} \cdot \mathrm{NH}_{3}}\left(\mathrm{NH}_{4}\right)_{2}(\mathrm{H}_{10} \mathrm{~B}_{10} \overbrace{\mathrm{S}}^{\mathrm{O}})\right.$

(1)

(III)

1,2-dibromoethane in ethanol afforded ammonium 7,7'-8, $8^{\prime}$-di- $\mu$-(1,2-dithioethane)bis-(7,8-dicarbaundecaborate(10)) (IV) which was precipitated in water in the form of the tetramethylammonium salt.

$\mathrm{III}+\mathrm{BrCH}_{2} \mathrm{CH}_{2} \mathrm{Br} \underset{\text { ethanol }}{\stackrel{\text { r.t. }}{\longrightarrow}} \underset{\mathrm{Me}_{4} \mathrm{NCl}_{\mathrm{H}} \mathrm{O}}{\longrightarrow}\left(\mathrm{NMe}_{4}\right)_{2}\left[\left(\mathrm{CH}_{2} \mathrm{~S}_{2} \mathrm{C}_{2} \mathrm{~B}_{4} \mathrm{H}_{10}\right]_{2}+\ldots\right.$

Reaction of III with excess of dichloromethane in ethanol in the presence of $\mathrm{NaI}$ afforded ammonium 7,7'-8, $8^{\prime}$-di- $\mu$-(dithiomethane)-bis-(7,8-dicarbaundecaborate(10)) (V) which was also precipitated in water in the form of the tetramethylammonium salt (eq. 3).

$$
\mathrm{III}+\mathrm{Cl}, \mathrm{CH}, \underset{\substack{\text { ethanol, } \mathrm{NaI} \\ \text { reflux }}}{\underset{\mathrm{Me}_{4} \mathrm{NCl}_{2} \mathrm{H}_{2} \mathrm{O}}{\longrightarrow}}\left(\mathrm{NMe}_{4}\right)_{2}\left(-\mathrm{CH}_{2} \mathrm{SCB}_{4} \mathrm{H}_{10} \mathrm{CS}-\right)_{2}+\text { other }
$$

Reaction of 1,2-dithiol-o-carborane (I) with 1.5 times the amount of $\mathrm{KOH}$ necessary to remove both protons in the dithiol molecule afforded a salt (presumably the dipotassium salt) which by reaction with 1,2-dibromoethane afforded IV and 1,1'-

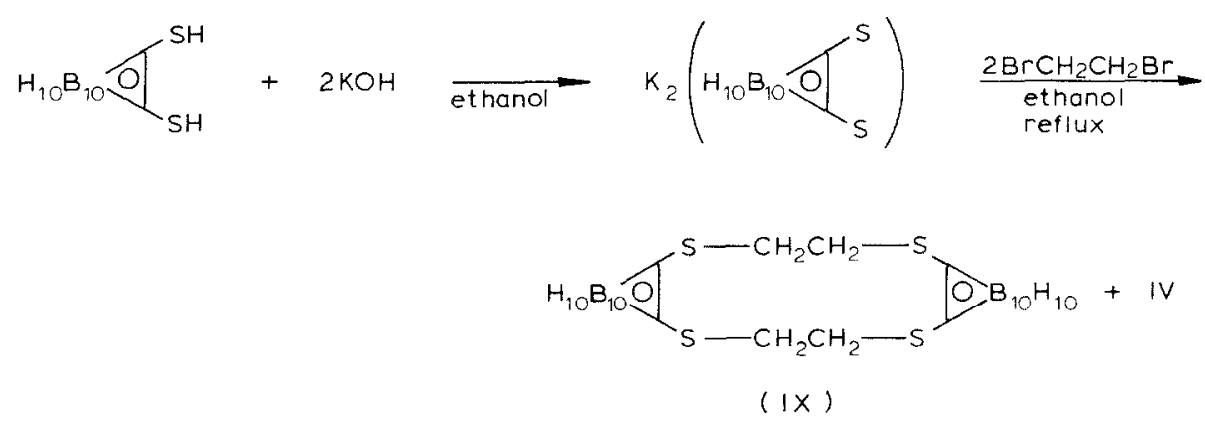

2,2'-di- $\mu$-(1,2-dithioethane)-bis-o-carborane (IX) (eq. 4) or by reaction with 1,2-di- 
$\mathrm{K}_{2}(\mathrm{H}_{10} \mathrm{~B}_{10} \overbrace{\mathrm{S}}^{\mathrm{S}})+\overbrace{\mathrm{CH}_{2} \mathrm{Br}}^{\mathrm{CH}_{2} \mathrm{Br}}$

( III)

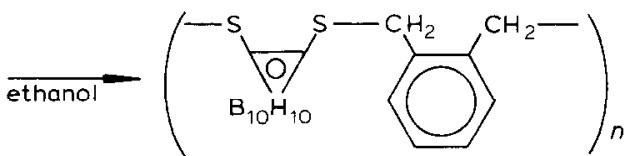

bromo- $o$-xylene afforded a compound insoluble in most of the usual solvents. Analysis of VIII indicated the composition shown in eq. 5.

Compounds IV and V were proven not to be monomeric by treatment with hydrochloric acid in an ether/water solution and by studying the mass spectra of the solid obtained after evaporation of the ether. In both cases, peaks assignable to fragments of the molecule bigger than the monomer and with higher intensity than the monomer have been observed (See Table 1), but no direct proof of the $n$ value has been obtained. Nevertheless, the authentic molecular dimers II and IX lead us to believe that IV and V are dimeric. Structural considerations of the $o$-xylyl moiety suggest that a polymeric structure for VIII may be more favorable than a dimer.

Reaction of 1,2-dithiol-o-carborane with $\mathrm{I}_{2}$ in benzene afforded 1,1'-2,2'-tetrathiobis-o-carborane (eq. 6)

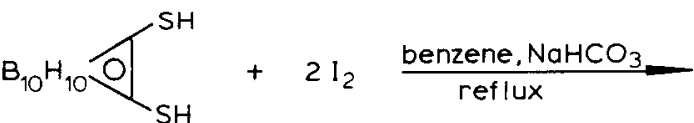

(1)

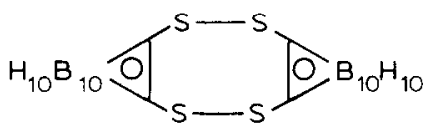

(II)

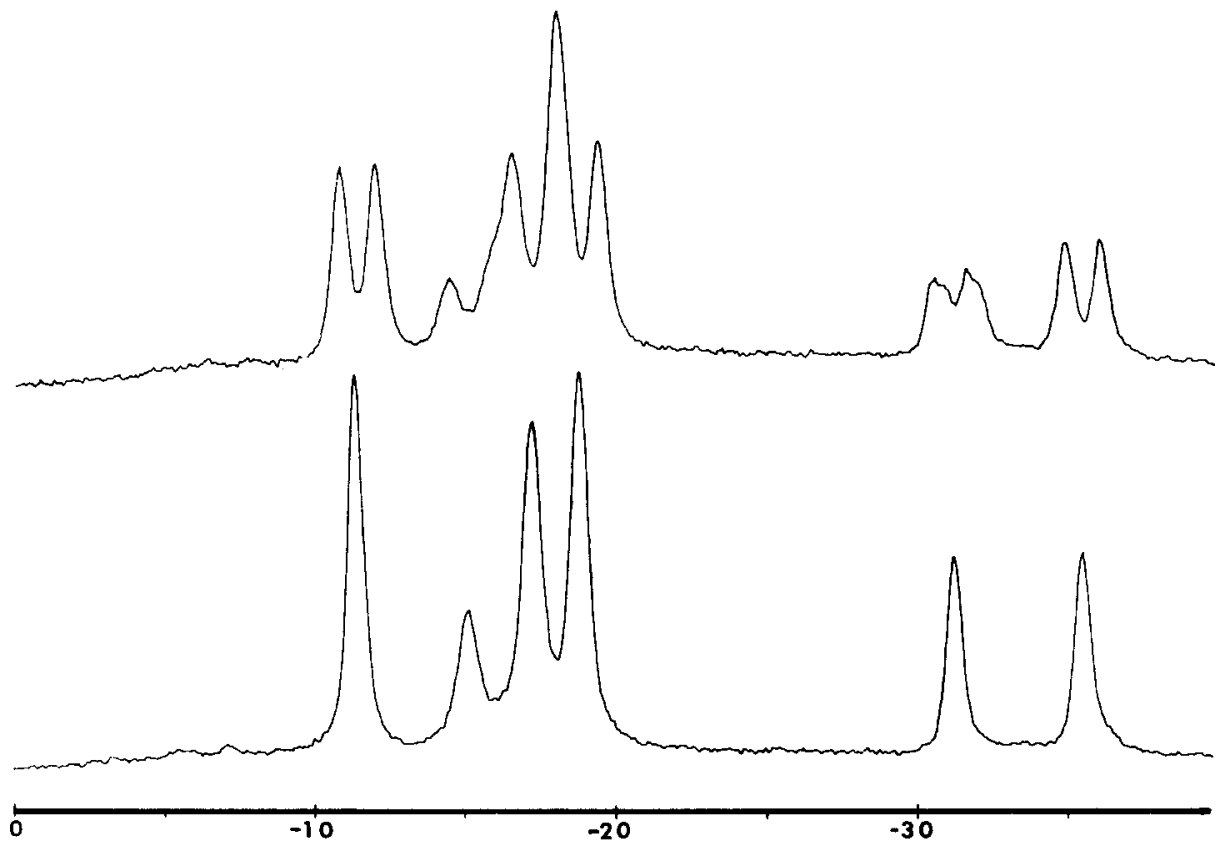

Fig. 2. The "'B NMR spectia (coupled and decuupled) of tetrantethylammonium $7,7^{\prime} ; 8,8^{\prime}-\mathrm{di}(\mathrm{di}-$ thiomethane)-bis-(7,8-dicarbaundecaborate(10)) in DMSO- $d_{6}$. Chemical shifts are relative to an external sample of $F_{3} B, O E t_{2}$. See Table 2 for coupling constants and chemical shifts. 
TABLE 2

${ }^{1}$ B NMR SPECTRAL DATA

\begin{tabular}{llllll}
\hline $\begin{array}{l}\text { Con- } \\
\text { pound }\end{array}$ Absorption h.i \\
p(ppm)
\end{tabular}

"Values referred to externat $\mathrm{BF}_{3} \cdot \mathrm{E}, \mathrm{O}$. " Solvent chloroform- $d$. "Solvent ethanol. "Solvent acetone- $d$. "Solvent dmsondl. ${ }^{\prime}$ Observed frequency $115 \mathrm{MHz} .{ }^{8}$ Observed frequency $28.7 \mathrm{MHz} . " J(\mathrm{~B}-\mathrm{H})$ are helow

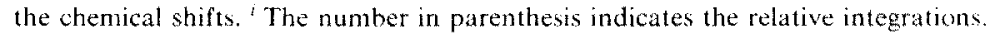

The "B NMR spectra (Table 2) clearly indicate that partial degradation of the $o$-carborane cage occurred in the synthesis of IV and $\mathrm{V}$, and the spectra show a $2 / 1 / 2 / 2 / 1 / 1$ pattern indicating a mirror plane going through three unique atoms and dividing the other six into 3 groups of two atoms each (See Fig. 2). The chemical shifts of these groups of atoms are close to those of the 7,8- $\mathrm{C}_{2}, \mathrm{~B}_{3} \mathrm{H}_{12}$ ion [12] and at the same time the ${ }^{11} B$ NMR spectra indicate that no degradation of the cage occurred in II, III and IX. The position of the B-H absorption band in the IR spectrum in compound VIII $\left(2570 \mathrm{~cm}^{-1}\right)$ agrees with what is expected for an undegraded carborane cage $\left(2560-2640 \mathrm{~cm}^{-1}\right.$ for substituted carborane and $2470-2550 \mathrm{~cm}^{-1}$ for the 7.8-dicarbaundecaborate(10)) [13]. We have found $2515-2510 \mathrm{~cm}^{-1}$ for partially degraded 1,2-dithioderivatives (compounds IV and V) and $2570 \mathrm{~cm}^{-1}$ for nondegraded derivatives (Table 3 ).

TABLE 3

INFRARED SPECTRAL DATA

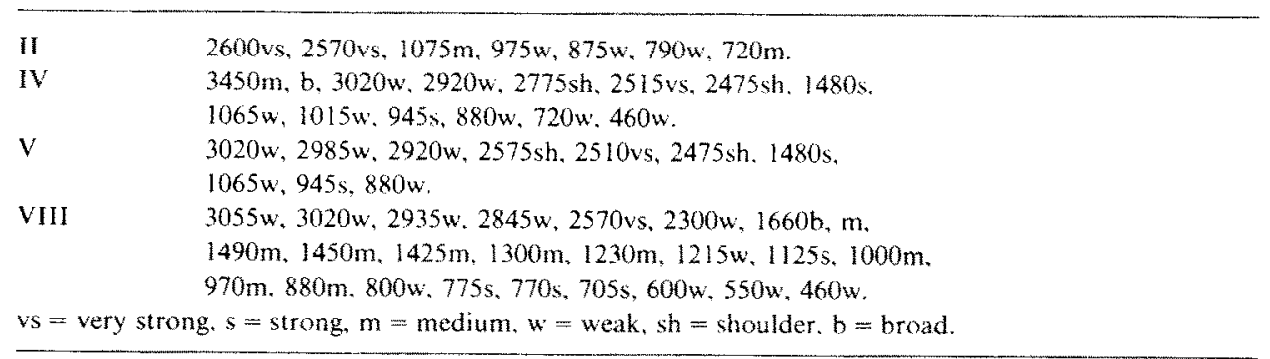


TABLE 4

'H NMR SPECTRAL DATA

\begin{tabular}{llllll} 
Compound & Absortion ${ }^{a}$ & & \\
\hline I $^{\text {h.e }}$ & & 3.73 & & & \\
IV $^{c . f}$ & $3.35(3)$ & $3.08(24)$ & 3.52 & $3.34(8)^{n}$ & -2.5 \\
V $^{d . g}$ & 3.94 & 3.77 & & & $3.10(12)$ \\
IX $^{d . g}$ & & 2.89 & & &
\end{tabular}

" Values are given in $\delta(\mathrm{ppm})$ referred to TMS. The number in parenthesis indicate the relative interpretations. ${ }^{b}$ Solvent chloroform- $d$. ${ }^{c}$ Solvent dmso- $d_{6} .{ }^{d}$ Solvent acetone-d. ${ }^{\circ}$ Observed frequency $60 \mathrm{MHz}$ f Observed frequency $360 \mathrm{MHz} .{ }^{8}$ Observed frequency $90 \mathrm{MHz} .{ }^{h}$ First 4 frequencies belonging to an $\mathrm{AB}$ system. Total integration 2.

The ${ }^{1} \mathrm{H}$ NMR (Table 4) is in accordance with the structures indicated, showing an $\mathrm{AB}$ pattern $(J 10.5 \mathrm{~Hz})$ in compound $\mathrm{V}$ and a more complicated pattern for compound IV with 21 observed absorptions, clearly indicative of an $\mathrm{AA}^{\prime} \mathrm{BB}^{\prime}$ [14] system as would be expected for the indicated geometry [15].

\section{Discussion}

As indicated earlier, the ultimate goal in the current research was to synthesize a molecule in which four metal centers are held in relatively close proximity in a fixed configuration. One approach to this goal is to use rigid $o$-carborane cages as building blocks and attach them to a macrocycle. Linkage of the cages to the macrocycle by both carbon atoms would be prevent rotation of the cages, and partial degradation would allow insertion of metal atoms in the cages to give the desired product.

One complication when four $o$-carborane cages are attached to a single framework is that upon degradation isomers will be produced which differ in the orientation of the cages with respect to the plane of the macrocycle. If $\alpha$ is used to designate a cage above the plane of the macrocylce and $\beta$ to designate one below the plane, the isomers can be described as $\alpha \alpha \alpha \alpha, \alpha \alpha \alpha \beta, \alpha \beta \alpha \beta$ and $\alpha \alpha \beta \beta$. Physical properties of these isomers may be expected to be quite similar and therefore separation of the various species following the degradation reaction would be difficult. A simpler approach, which is described here as an initial step in the program, is to focus on a two cage system in which, after degradation, only two isomers would exist in the degradation mixture, the $\alpha \alpha$ and the $\alpha \beta$ species, and the severity of the separation problem would be significantly lessened.

For a number of reasons, 1,2-dithiol-o-carborane is attractive as the choice of a carborane cage: (a) there are two reactive groups present, (b) the presence of lone pairs and accessible $d$-orbitals on the sulfur could facilitate interaction between cages, and (c) the compound $\left[\left(\mathrm{C}_{2} \mathrm{H}_{5}\right)_{4} \mathrm{~N}\right]_{2} \mathrm{Ni}\left(\mathrm{B}_{10} \mathrm{H}_{10} \mathrm{C}_{2} \mathrm{~S}_{2}\right)_{2}$ [17] could possibly be utilized as a template, if necessary, in order to obtain the desired geometry. The template reaction was based on the work by Thompson and Busch [18], from which the following reaction was projected.

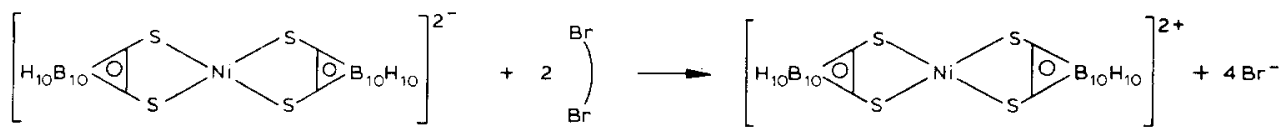




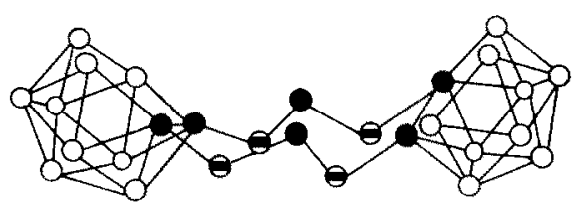

OC OS OB

Fig. 3. Proposed structure of the $\alpha, \alpha$ isomer of $7,7^{\prime} ; 8,8^{\prime}$-di-(dithiomethane)-bis-(7,8-dicarbaundecaborate(10))ion. The hydrogen atoms have been omitted for clarity.

In order to explore the reaction conditions needed to produce a two cage ligand. $\alpha, \alpha^{\prime}$-dibromo-o-xylene was employed instead of the 1,2-bis-bromomethyl-o-carborane since the similarities in their geometries suggested that the two would undergo analogous reactions and the expensive carborane material could be conserved. The reaction of $\mathrm{A}$ with $\alpha, \alpha^{\prime}$-dibromo- $o$-xylene produced a white solid that was very insoluble (VIII) and subsequent reaction with 1,2-dibromoethane led to IV in a $60 \%$ yield.

As it turned out, the same compounds could be obtained more simply by means of the reaction of III with the indicated reagents, which implies that the presence of a template was unnecessary, or that upon the formation of the thioether, the $\mathrm{S}-\mathrm{Ni}$ bond was broken with the loss of the template effect. Either would explain the formation of VIII. However, in this case the steric effects operating would favor a more relaxed structure leading to a polymer with the carboranyl moiety undegraded [19]. On the other hand, with a shorter bridge such as $-\mathrm{CH}_{2}-$ or $\mathrm{CH}_{2} \mathrm{CH}_{2}-$ (IV, V), the ring closure is favored, making borons 3 or 6 very susceptible to nucleophilic attack and resulting in a partially degraded molecule. The fact that IX exists and is stable in ethanol implies that the partial degradation is a consequence of the mechanism employed in the ring formation, and that one or more other mechanisms exist in which the partial degradation does not take place. In Fig. 3 one of the isomers of $\mathrm{V}$ is represented.

The degradation that occurred resulting in IV and $V$ was unexpected. The methods described in the literature to partially degrade o-carborane all require nucleophilic agents such as methoxide, trialkylamines, hydrazine, ammonia or similar compounds [16] whereas the reactions indicated in equations 2 and 3 proceeded to the degraded carborane without the introduction of a base. The only step in which a conventional base (ammonia) was employed was in the formation of III, and in this case the analyses and the " B NMR spectra clearly indicated that the product contained a non-degraded $o$-carborane cage.

Up to now few papers have appeared concerning the chemistry of the thiol (mono and di) derivatives of 0 -carborane [20]. As can be seen from the present work. the chemistry of the 1,2-dithiol-o-carborane (I) exhibits previously unknown reactions compared to other known derivatives of o-carborane. Even the chemistry of I seems to differ from that of 1 -thio-o-carborane. For example, Zakharkin and coworkers do not indicate any problem in the oxidation of ${ }^{R}{ }_{\rho^{S-}}^{S{ }^{+}}$with $I_{2}$ in order to obtain the disulfide [21]. However, reaction of III with iodine in ethanol gives a salt, the " $B$ NMR of which no longer corresponds to undegraded carborane [22]. It is our 
opinion that it is the possibility of ring formation together with the presence of lone pairs and available $d$-orbitals of the sulfur that causes these differences. A plausible explanation may be that the increased stability of the molecule is to be expected as a result of the delocalization of the sulfur lone pair. This could occur through overlap of the $s$-orbitals with those of the open face of the degraded cage. This delocalization is less feasible when the thiols are not adjacent to the boron atom which is removed upon degradation. Recently, Hermanek and coworkers [23] have synthesized 9,12$\left(\mathrm{CH}_{2} \mathrm{~S}_{2}\right)-1,2-\mathrm{C}_{2} \mathrm{~B}_{10} \mathrm{H}_{10}$ which supports our explanation.

Our results further suggest to us that an interaction between the two cages exists in compounds II, IV and V. We believe that this interaction will be increased if the linking atoms, instead of being saturated carbons, are atoms with available $d$-orbitals and lone pair electrons. Current efforts are being directed towards obtaining compounds with these characteristics, and to solve the stereochemistry of the $\alpha \alpha$ and $\alpha \beta$ isomers.

\section{Acknowledgement}

FT thanks the Spanish Ministerio de Universidades e Investigacion for a Grant. Acknowledgement is made to the Petroleum Research Fund, administered by the American Chemical Society, for partial support of this research through grant No. 12136-AC3. The assistance of Professor Robert C. Taylor in the revision of the manuscript is also acknowledged.

\section{References}

1 G.W. Parshall, Homogeneous Catalysis, Wiley-Interscience 1980.

2 E.L. Muetterties, Science, 196 (1977) 839.

3 (a) T.E. Paxon and M.F. Hawthorne, J. Am. Chem. Soc. 96 (1974) 4674; (b) E.L. Hoel and M.F. Hawthorne, J. Am. Chem. Soc. 96 (1974) 4676; (c) L.C. Zakharkin and T.B. Agakhanova, Zh. Obshch. Khim. 47 (1977) 2396; (d) E.S. Chandrasekaran, D.A. Thompson and R.W. Rudolph, Inorg. Chem., 17 (1978) 760 .

(e) L.C. Zakharkin, T.B. Agakhanova. Izv. Akad. Nauk SSSR, Ser. Khim, 9 (1978) 2151.

4 R.T. Baker, R.E. King III, C. Knobler, C.A. O'Con and M.F. Hawthorne, J. Am. Chem. Soc., 100 (1978) 8266.

5 E.L. Muetterties, Boron Hydride Chemistry, Academic Press, New York, (1975) p. 383.

6 (a) $\mathrm{H}_{2} \mathrm{P}=$ porphyrin core which is followed by substituent at the meso positions; (b) R.C. Haushalter and R.W. Rudolph, J. Am. Chem. Soc., 100 (1978) 4628.

7 R.C. Haushalter and R.W. Rudolph, J. Am. Chem. Soc., 101 (1979) 7080.

8 H.D. Smith, Jr., C.O. Oberland and S. Papetti, Inorg. Chem., 5 (1966) 1013.

9 In some cases after two filtrations some turbidity remained. In these cases the procedure was continued.

10 This proportion was calculated from the relative areas of the "B NMR spectrum which showed peaks at $\delta(\mathrm{ppm})-2.9 ;-5.9 ;-7.5 ;-9.08 ;-11.41 ;-13.0 ;-16.27 ;-17.75($ total area $=25)$ and -33.46 ; -34.73 (total area $=2$ ). Proton NMR spectra showed absorptions at $\delta(\mathrm{ppm}) 7.51 ; 7.26 ; 7.03 ; 4.80$; 4.43 and 4.14 among other smaller intensity.

11 These values assume the absorptions at -32.51 and $-36.02 \mathrm{ppm}$ are due to borons 10 and 1 respectively, in IV and the absorption at -2.03 is due to two borons in III. probably the 9,12 borons. See Table 2.

12 (a) D.V. Howe, C.J. Jones, R.J. Wiersema and M.F. Hawthorne, Inorg. Chem., 10 (1971) 2516; (b) A.R. Siedle, G M. Bodner and I. J. Todd, I Organometal Chem. 33 (1971) 137.

13 L.J. Zakharkin and A.V. Grebennikov., Izv, Akad. Nauk. SSSR, Ser. Khim, 11 (1966) 2019.

14 J.V. Emsley, J. Feeney and L.H. Sutcliffe, High Resolution Nuclear Magnetic Resonance Spectroscopy, Vol. 1, Pergamon Press, (1965) pp. 399-415. 
15 The 'H NMR spectrum cannot provide information about the $n$ value for this compound or whether the vacant positions in the carborane cages are cis or trans, since in all of these cases an $\mathrm{AA}^{\prime} \mathrm{BB}^{\prime}$ spectrum is expected with very similar coupling constants.

16 R.N. Grimes, Carboranes, Academic Press, (1970) p. 193.

17 H.D. Smith, Jr., M.A. Robinson and S. Papetti, Inorg. Chem. 6 (1967) 1014.

18 M.C. Thompson and D.H. Busch. J. Am. Chem. Soc., 86 (1964) 3651.

19 The same type of reaction was obtained using 1,4-dibromobutane.

20 For a review see Ref. 16.

21 L.J. Zakharkin and G.G. Zhigareva., Izv. Akad. Nauk SSSR. Ser. Khim., 6 (1967) 1358.

22 Under $\mathrm{N}_{2}$, compound III was dissolved in ethanol and a titration with an ehanolic solution of $\mathrm{I}_{2}$ was followed. The purple iodine color vanished in contact with the iodine salt. Following the coloration of the solution, the stoichiometry was determined to be $1 / 1$. Upon evaporation of the solution the "B NMR of the remaining solid in DMSO- $d_{6}$ showed broad absorptions no longer belonging to a o-carborane derivative.

23 J. Plesek. Z. Janousek and S. Hermanek, Collect. Czech Chem. Commun. 45 (1980) 1775. 